\title{
EFFECT OF LOW-, MODERATE-, AND HIGH-INTENSITY EXERCISE ON ATRIAL NATRIURETIC PEPTIDE (ANP) AND SARCOPLASMIC/ENDOPLASMIC RETICULUM CALCIUM-ATPaSe 2a (SERCA2a) GENE EXPRESSION IN WISTAR RAT CARDIAC MUSCLE
}

\author{
Averina Octaxena Aslani ${ }^{1}$, Hanna Goenawan ${ }^{2}$, Nova Sylviana ${ }^{2}$ \\ ${ }^{1}$ Undergraduate Program, Faculty of Medicine, Universitas Padjadjaran, Bandung, Indonesia \\ ${ }^{2}$ Physiology Division, Department of Basic Medical Science, Faculty of Medicine, Universitas Padjadjaran, Bandung, \\ Indonesia
}

\begin{abstract}
Exercise is one of the factors that affect cardiovascular health. Exercise has been proven to reduce the number of cardiovascular diseases. However, it is also known that doing intense exercise has an adverse effect on heart health which can increase the risk of cardiovascular disease. While doing exercise, there is compensation from the heart itself by producing substances to maintain the heart to remain functional, known as cardiac biomarkers, including ANP and SERCA2a. Thus far, the recommended intensity is moderate-intensity exercise, which is optimal for heart health, but this recommendation has not been supported by biomolecular study. Therefore, this research was conducted. This study was done using semi-quantitative analytic method and experimental study design. Total of 24 male wistar rats were divided randomly into 4 groups: 1 control group $(0 \mathrm{~m} / \mathrm{min})$ and 3 exercise groups (low-: 10m/min, moderate-: $20 \mathrm{~m} / \mathrm{min}$, high-intensity exercise: $30 \mathrm{~m} / \mathrm{min}$ ). All groups received $30 \mathrm{~min} /$ day running, 5x/week for 12 weeks. The rats were terminated under anaesthesia, cardiac muscle extraction was done from left ventricle, and gene expression of ANP and SERCA2a is studied. Statistical analysis was done using SPSS software with one-way ANOVA followed by post hoc comparisons if the p-values < 0.05. The expression of ANP increased but insignificant in low-, moderate-, and high-intensity exercise group of rat $(0.872 \pm 0.034 \mathrm{vs}$ $0.901 \pm 0.018$ vs $0.916 \pm 0.015$ vs $0.938 \pm 0.025 ; p=0.304)$. The expression of SERCA2a also increased insignificantly in low-, moderate-, and high-intensity exercise group of rat $(1.044 \pm 0.019 \mathrm{vs}$ $1.051 \pm 0.015$ vs $1.063 \pm 0.011$ vs 1.082 $\pm 0.027 ; p=0.493$ ). Different exercise intensity didn't have significant effect on ANP and SERCA2a expression in rat cardiac muscle.
\end{abstract}

Keywords: cardiac, exercise, intensity, ANP, SERCA

Korespondensi: Averina Octaxena Aslani, E-mail: hanna@ unpad.ac.id , Fakultas Kedokteran Universitas Padjadjaran. Jalan Raya Jatinangor Km 21, Sumedang, Jawa Barat, Indonesia. 


\section{INTRODUCTION}

According to WHO, cardiovascular disease (CVD) is a major cause of death in the world $^{1}$. The risk factors of CVD include high calorie diet, lack of physical activity, smoking, cholesterol, hypertension, and others. Lack of physical activity is the fourth highest risk factor that enhance the risk of death in the world after high blood pressure, smoking, and high blood glucose ${ }^{1-3}$. Studies show that exercise can decrease the risks of cardiovascular disease. Regular exercise has important roles in improving the cardiac health and preventing the cardiovascular disease ${ }^{1,4-6}$. However, the intense exercise also can cause adverse effects on the cardiovascular itself, the heart and large blood vessels undergo pathological structure remodeling that actually increase the risk of cardiovascular disease ${ }^{4}$.

Exercise is useful for improving physical fitness and enhances the cardiac function ${ }^{5}$. Exercise at particular intensity alter the components of Atrial Natriuretic Peptide (ANP) and Sarcoplasmic/Endoplasmic Reticulum Calcium-ATPase (SERCA2a) as the biomarkers for cardiac function. ANP is natriuretic peptide that released from heart when atrium and ventricle distention by neuro humoral stimuli, commonly caused by exercise $^{7,8}$. It also acts as an indicator of the functionality degree of cardiac function in patients with cardiac disease 9 . The increase of this hormone is associated with better survival in patients with chronic heart failure (CHF). The worse the progression of heart failure, ANP will also fail to compensate ${ }^{7,8}$. Cardiac SERCA2a plays a central role in myocardial contractility. Decreases in the expression levels of SERCA2a have been observed in a variety of pathological conditions. Thus, SERCA2a is a major regulator of intracellular $\mathrm{Ca}^{2+}$ homeostasis, and changes in the expression and activity of the SERCA pump contribute to the decreased SERCA2a content and cardiac dysfunction during pathogenesis $^{10,11}$.

The intensity of exercise will affect the energy used. Various researches have studied about the various benefits of exercise, especially on molecular and cellular mechanisms in the body. However, future researches are needed to determine the optimal intensity of exercise ${ }^{12,13}$. Thus far, moderate-intensity exercise is recommended as the optimal intensity of exercise for improving the physical fitness and preventing the cardiovascular disease ${ }^{3,14}$. However, there is no study about the effect of the different exercise intensity on ANP and SERCA2a expression in rat cardiac muscle ${ }^{8,14}$. Therefore, this study was conducted to identify the cardiac function through the change in ANP and SERCA2a expression in rat cardiac muscle that received exercise at low-, moderate-, or high-intensity.

\section{MATERIAL AND METHODS Animals}

All the animal experiment procedures in this study were approved by Health Research Ethics Committee Faculty of Medicine Universitas Padjadjaran No 986/UN6.KEP/EC/2018 and also followed Guide for the Care and Use of Laboratory Animal (The National Academic press, 2011). Total of 24 male wistar rats (Biofarma Laboratory, Bandung, Indonesia) at the age of 8 weeks with body weight 201-250 gram used in the present study. Every 5 rats were kept in a cage $(40 \mathrm{~cm} \times 70 \mathrm{~cm} \times 40 \mathrm{~cm})$ with food and water available ad libitum. Animals were kept under a $12 \mathrm{~h}$ light-12 h dark cycle and room temperature. After done the treadmill habituation for 2 weeks, the rats were divided randomly into four groups: control group $(0 \mathrm{~m} / \mathrm{min})$ and 3 exercise groups low-: $10 \mathrm{~m} / \mathrm{min}$, moderate-: $20 \mathrm{~m} / \mathrm{min}$, highintensity: $30 \mathrm{~m} / \mathrm{min})^{15}$.

\section{Treadmill apparatus and training protocol}

The authors used animal treadmill machine (IDEAS, Bandung, Indonesia) for rat. The treadmill machine is divided into five lanes. All rats were habituated for two weeks by placing rats in the running treadmill machine at a speed that gradually increase every three days. At the end of habituation, rats were divided randomly into four groups (control, low-, moderate-, high-intensity). The 
rats were run in individual lane according to the group (control: $0 \mathrm{~m} / \mathrm{min}$, low-: $10 \mathrm{~m} / \mathrm{min}$, moderate-: $20 \mathrm{~m} / \mathrm{min}$, high-intensity: 30 $\mathrm{m} / \mathrm{min})^{15}$. All groups were run for $30 \mathrm{~min} /$ day, $5 \mathrm{x} /$ week for 12 weeks.

\section{Measurement of ANP and SERCA2a gene expression}

By the end of training period, all rat groups (control and exercise) were terminated under inhaled isoflurane anesthesia and then the hearts were isolated. The hearts were kept in eppendorf tubes, snap-frozen in liquidnitrogen then stored at $-80^{\circ} \mathrm{C}$ until RNA isolation.
Total RNA were extracted from the cardiac muscle using TRIzol reagent (Thermo Fisher Scientific, Carlsbad, CA). Semiquantitative PCR was performed using the RT PCR Kit (Bioline, London., UK). The gel electrophoresis band of the PCR products of each gene was visualized by BioDocAnalyze gel analysis software and quantified using ImageJ Software (NIH). The gene expression level of the samples was normalized by GAPDH mRNA level. The sequences and other information about the primers including ANP, SERCA2a, and GAPDH are listed in Table 1.

Table 1. Primers for real-time polymerase chain reaction

\begin{tabular}{llll}
\hline Gene & Sequence & Tm( $\left.{ }^{\circ} \mathbf{C}\right)$ & $\begin{array}{l}\text { Product } \\
(\mathbf{b p})\end{array}$ \\
\hline ANP & F 5'- ACC TGC TAG ACC ACC TGG AG -3' & 61 & 227 \\
& R 5'- AGC CCT CAG TTT GCT TTT CA -3' & & 175 \\
\hline SERCA2a & F 5'- ATT GTT CGA AGT CTG CCT TCT GTG G -3' & 64 & \\
& R 5'- CAT AGG TTG ATC CAG TTA TGG TAA A -3' & & 177 \\
\hline GAPDH & F 5'- GTTACCAGGGCTGCCTTCTC -3' & 61 & \\
& R 5'- GATGGTGATGGGTTTCCCGT -3' & & \\
\hline
\end{tabular}

*Tm : temperature melting

$* * \mathrm{Bp}$ : base product

\section{Statistical analysis}

All statistics were computed using SPSS version 25.0 software for Windows. Quantitative data were expressed as the means \pm standard error of mean (means \pm SEM). Data were statistically analyzed with one-way ANOVA followed by post hoc comparisons using Dunnett. The p-values $<0.05$ were considered to be significant.

\section{RESULT}

The ANP expression level in control group was $0.872 \pm 0.034$, low-intensity group was $0.901 \pm 0.018$, moderate-intensity group was $0.916 \pm 0.015$ and high-intensity group was $0.938 \pm 0.025$. ANP mRNA expression in low-intensity group increased compared with the control group although statistically not significant, also in moderate- and high- intensity group, that ANP expression increased but statistically not significant. The results showed that all exercise intensity group didn't have significant effect on ANP mRNA expression $(\mathrm{p}=0.304)$.

The SERCA2a expression level in control group was $1.044 \pm 0.019$, lowintensity group was $1.051 \pm 0.015$, moderateintensity group was $1.063 \pm 0.011$ and highintensity group was $1.082 \pm 0.027$. SERCA2a mRNA expression in low-intensity group increased compared with the control group although statistically not significant, same as in moderate- and high-intensity group, SERCA2a expression also increased insignificantly compared with the control group. The results showed that all exercise intensity group didn't have significant effect on SERCA2a mRNA expression $(\mathrm{p}=0.493)$. 

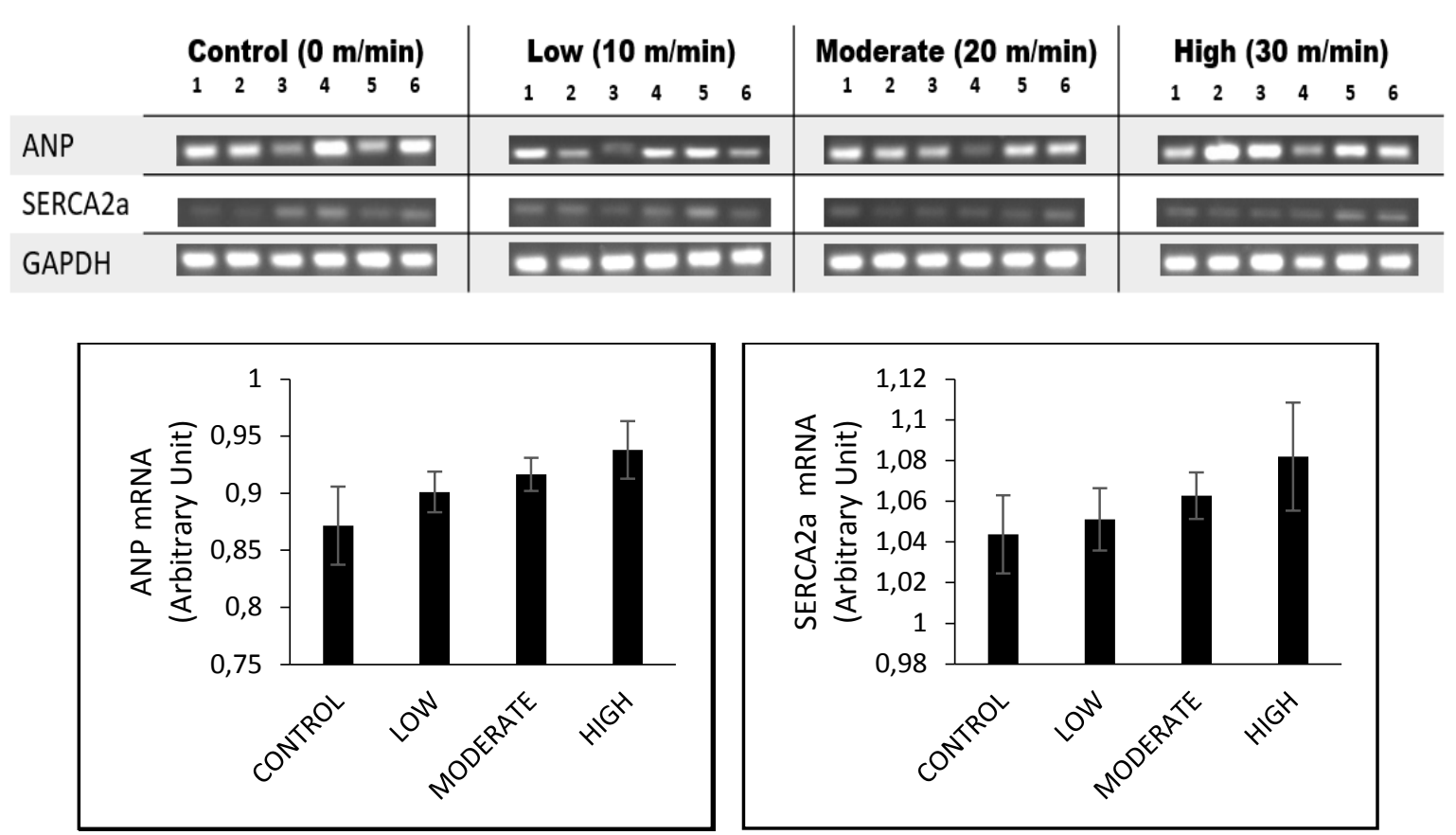

Figure 1. PCR Result of ANP and SERCA2a gene expression.

Values are expressed as mean \pm SEM.

\section{DISCUSSION}

Exercise influences the body homeostasis thus can cause the cardiovascular physiologic response. The needs of myocardial metabolic will increase during physical exercise and cause increasing myocardial oxygen consumption. When the heart rate increases, myocardial oxygen consumption increases, so that the blood flows will also increase through two mechanisms: (1)Increasing myocardial contraction due to response to exercise increase the blood flow to the coronary circulation. (2)Vasodilation of arterioles that supply the myocardium will increase the blood flow and decrease the vascular resistance. Increased heart rate is influenced by the intensity of exercise therefore the intensity of exercise will also affect myocardial needs including myocardial oxygen consumption ${ }^{14}$. During exercise, adaptations occur to meet the oxygen demand in myocardium. Therefore, cardiac myocytes undergo an increase in oxidative stress in the body after doing exercise. However, the threshold of the intensity that starts to show an increase in oxidative stress levels is still unknown yet ${ }^{16}$. The chronic response to exercise is obtained after individuals doing the exercise regularly for 8 to 12 weeks ${ }^{17}$.
The studies of patients with congestive heart failure (CHF) showed the increased concentration of ANP in response to exercise. Exercise is accepted as a strong stimulus for the release of ANP. The pro-ANP levels increased gradually after doing exercises, these findings may represent a beneficial effect of increasing the capacity of ANP in CHF patients after completion of exercise. ${ }^{18}$ Recent study also showed there was the increase of mRNA ANP levels in hamster cardiac muscle with $\mathrm{CHF}^{19}$.

In healthy humans, it has been shown that ANP increase during and immediately following the exercise. ANP levels increased significantly in subjects who did the exercise. ANP increased rapidly after 5-10 minutes of exercise. A study conducted by Follenius et al. showed a rapid increase in plasma ANP levels was induced by both high $(75 \%$ $\left.\mathrm{VO}_{2} \max \right)$ and lower work levels $(55 \%$ $\left.\mathrm{VO}_{2} \max \right)^{20}$. In Follenius et al. research also has the similar result with our study which the increase of ANP level according to the intensity of exercise were not significantly different in either case ${ }^{20}$.

In study conducted by Haufe et al. with overweight and obese subjects were measured the pro-ANP levels in rest and after exhaustive exercise using a bicycle ergometer 
until exhaustion $^{21}$. The study showed that after six months weight loss and exercise, the pro-ANP levels did not change, however, the acute measurement showed increased in proANP levels during exercise both before and after dietary intervention. This study concluded that acute exercise significantly increased the pro-ANP levels in overweight and obese patients, but chronically has no effect and there could be dietary influencing ${ }^{21}$.

Study from Bordbar et al. analyze the effects of eight weeks training exercise on the natriuretic peptide release ${ }^{22}$. This study showed that natriuretic peptide significantly increased immediately after aerobic exercise, but after eight weeks of exercise it decreased. The result showed that in chronic exercise, natriuretic peptide levels return to baseline ${ }^{22}$. Possibly, in chronic exercise, the adaptation process already occurred, therefore can cause the lower level of ANP expression as in this study.

SERCA2a regulates the transport of $\mathrm{Ca}^{2+}$ out of the cytosol into the sarcoplasmic reticulum just after the myocardial contraction has occurred. The increase of SERCA2a in response to exercise could be an adaptation to the heart to prevent any dysfunction ${ }^{23}$. In this study, SERCA2a mRNA expression increased in exercise group although the different level of intensity among the group was statistically insignificant. Similarly in a study on the heart of obese rat that do running also showed the increase in SERCA2 mRNA levels, suggesting that regular exercise has a beneficial effect on cardiac function ${ }^{24}$.

Study that analyzes the effect of different exercise intensity on SERCA2a gene expression is a quite rare until now. Kubo et $a l$. conducted the study in Sprague-Dawley rats trained 60 min per day, 5 days per week for six weeks at moderate- and high-intensity showed significantly increased than control in SERCA2a mRNA expression on gastrocnemius muscle after exercise for both intensity groups ${ }^{25}$. Similarly as study from Wisloff et al. in infarct Sprague-Dawley rats which ran on a treadmill 1.5 hours per day, 5 days per week for eight weeks showed that aerobic endurance training significantly increased the myocardial SERCA2 ${ }^{26}$. Study from Medeiros et al. male wild-type (WT) mice that performed swimming 5 days per week for eight weeks also showed a significant increase in SERCA2 expression. ${ }^{27}$ Possibly, the duration of exercise in this study was shorter compared with previous papers (30 min vs 60-90 $\mathrm{min}$ ) cause the lower level of SERCA2a expression ${ }^{25,26}$.

\section{CONCLUSION}

The expression of ANP and SERCA2a in rat cardiac muscle were not affected by the different exercise intensity. Further experiments are needed to analyze the correlation between ANP and SERCA2a. Also the histopathology or immunohistochemistry examination of rat cardiac muscle need to conduct for further analysis which exercise intensity is the most optimal for cardiovascular health.

\section{ACKNOWLEDGMENTS}

The authors thank to Mr. Edi Sukmana Animal Physiology Laboratory, Faculty of Medicine, Universitas Padjadjaran; and Susianti SSi, Central Laboratory, Universitas Padjadjaran for technical assistance of this study.

\section{FUNDING}

This study was funded by Hibah Internal UNPAD (HIU) RKDU for $\mathrm{HG}$ and NS.

\section{CONFLICT OF INTEREST}

The authors declare no conflict of interest. 


\section{REFERENCES}

1. Mendis S, Puska P, Norrving B. Global Atlas on Cardiovascular Disease Prevention and Control. Geneva: World Health Organization; 2011. 164 p.

2. World Health Organization. Global health risks: mortality and burden of disease attributable to selected major risks. Geneva: World Health Organization; 2009.

3. Piepoli MF, Hoes AW, Agewall S, Albus C, Brotons C, Catapano AL, et al. European Guidelines on cardiovascular disease prevention in clinical practice: The Sixth Joint Task Force of the European Society of Cardiology and Other Societies on Cardiovascular Disease Prevention in Clinical Practice (constituted by representatives of 10 societies and by invited experts) Developed with the special contribution of the European Association for Cardiovascular Prevention \& Rehabilitation(EACPR). Eur Heart J. 2016;37(29):2315-2381.

4. Eijsvogels TM, Fernandez AB, Thompson PD. Are there deleterious cardiac effects of acute and chronic endurance exercise?. Physiological reviews. 2016;96(1):99-125.

5. World Health Organization. Global recommendations on physical activity for health. 2010.

6. Myers J. Cardiology patient pages. Exercise and cardiovascular health. Circulation. 2003;107(1):e2-5.

7. Arjamaa O. Physiology of natriuretic peptides: The volume overload hypothesis revisited. World $J$ cardiol. 2014;6(1):4-7.

8. Lee NS, Daniels LB. Current Understanding of the Compensatory Actions of Cardiac Natriuretic Peptides in Cardiac Failure: A Clinical Perspective. Cardiac failure review. 2016;2(1):14-19.

9. de Almeida JC, Alves CL, de Abreu LC, Sato MA, Fonseca FL, de Mello Monteiro CB, et al. Involvement of the atrial natriuretic peptide in cardiovascular pathophysiology and its relationship with exercise. Int archives of med. 2012;5(1):4.

10. Bravo R, Parra V, Gatica D, Rodriguez AE, Torrealba N, Paredes F, et al. Endoplasmic reticulum and the unfolded protein response: dynamics and metabolic integration. Int rev of cell and mol biol. 2013;301:215-90.

11. Periasamy M, Kalyanasundaram A. SERCA pump isoforms: their role in calcium transport and disease. Muscle \& nerve. 2007;35(4):430-42.

12. Tao L, Bei Y, Zhang H, Xiao J, Li X. Exercise for the heart: signaling pathways.

Oncotarget. 2015;6(25):20773-20784.

13. Ensign WY, McNamara DJ, Fernandez ML. Exercise improves plasma lipid profiles and modifies lipoprotein composition in guinea pigs. $J$ Nutr Biochem. 2002;13(12):747-53.

14. Plowman SA, Smith DL. Exercise physiology for health fitness and performance: Lippincott Williams \& Wilkins; 2013.

15. Lesmana R, Iwasaki T, Iizuka Y, Amano I, Shimokawa N, Koibuchi N. The change in thyroid hormone signaling by altered training intensity in male rat skeletal muscle. Endocr $J$. 2016;63(8):727-38.

16. Zagorska A, Dulak J. HIF-1: the knowns and unknowns of hypoxia sensing. Acta biochim Pol. 2004;51(3):563-85.

17. Dery MA, Michaud MD, Richard DE. Hypoxia-inducible factor 1: regulation by hypoxic and non-hypoxic activators. Int J Biochem Cell Biol. 2005;37(3):53540.

18. De Almeida JC, Alves CL, de Abreu LC, Sato MA, Fonseca FL, de Mello Monteiro $\mathrm{CB}$, et al. Involvement of the atrial natriuretic peptide in cardiovascular pathophysiology and its relationship with exercise. Int Archs Med. 2012;5(1):4.

19. Kinnunen P, Vuolteenaho O, Uusimaa P, Ruskoaho H. Passive mechanical stretch releases atrial natriuretic peptide from rat 
ventricular myocardium. Circ research. 1992;70(6):1244-53.

20. Follenius M, Brandenberger G. Increase in atrial natriuretic peptide in response to physical exercise. Eur J Appl Physiol Occup Physiol. 1988;57(2):159-162.

21. Haufe S, Kaminski J, Utz W, Haas V, Mähler A, Daniels MA, et al. Differential response of the natriuretic peptide system to weight loss and exercise in overweight or obese patients. J Hypertens. 2015;33(7):1458-64.

22. Bordbar S, Bigi MA, Aslani A, Rahimi E, Ahmadi N. Effect of endurance and strength exercise on release of brain natriuretic peptide. $J$ Cardiovasc Dis Res. 2012;3(1):22-5.

23. Gamu D, Bombardier E, Smith IC, Fajardo VA, Tupling AR. Sarcolipin provides a novel muscle-based mechanism for adaptive thermogenesis. Exerc Sport Sci Rev. 2014;42(3):136-42.

24. Frayon S, Cueille C, Davicco M-J, Coxam V, Barlet J-P, Garel J-M. Increased expression of SERCA2
mRNA in hearts of genetically obese Zucker rats after a moderate treadmill running. Sci Sports. 2004;19(1):34-42.

25. Kubo H, Libonati JR, Kendrick ZV, Paolone A, Gaughan JP, Houser SR. Differential effects of exercise training on skeletal muscle SERCA gene expression. Med Sci Sports Exerc. 2003;35(1):27-31.

26. Wisloff U, Loennechen JP, Currie S, Smith GL, Ellingsen O. Aerobic exercise reduces cardiomyocyte hypertrophy and increases contractility, $\mathrm{Ca} 2+$ sensitivity and SERCA-2 in rat after myocardial infarction. Cardiovasc Res. 2002;54(1):162-74.

27. Medeiros A, Rolim NP, Oliveira RS, Rosa KT, Mattos KC, Casarini DE, et al. Exercise training delays cardiac dysfunction and prevents calcium handling abnormalities in sympathetic hyperactivity-induced heart failure mice. J Appl Physiol.

(1985). 2008;104(1):103-9. 